Article

\title{
"Look How Many Gays There Are Here": Digital Technologies and Non-Heterosexual Space in Haikou
}

\author{
James Cummings \\ School of Art, Media and American Studies, University of East Anglia, Norwich, NR4 7TJ, UK; E-Mail: j.cummings@uea.ac.uk
}

Submitted: 16 July 2020 | Accepted: 17 September 2020 | Published: 15 December 2020

\begin{abstract}
This article explores the capacities of digital technologies to disrupt, redefine and multiply urban spaces, creating new ways of seeing and experiencing cities. Based on ethnographic research into the lives of men who desire men in Haikou, People's Republic of China, and their uses of the location-aware dating app Blued, I show how the city is produced anew as a space imagined and engaged in relation to the perceptible presence of other men who desire men. In a sociopolitical context in which non-heterosexual lives are largely invisible in public spaces, the digitally mediated visibility of Blued users to one another invites a range of social practices through which urban spaces, as well as spatial categories of 'the urban' and 'the rural,' are reproduced at the intersections of sexuality, space and digital technologies. With its empirical focus on an 'ordinary' city in a non-Western context, this article challenges both the Eurocentricity of much digital geographies research and its tendency to focus on global cities.
\end{abstract}

\section{Keywords}

China; digital; gay; Haikou; Hainan; sexuality; space; technology

Issue

This article is part of the issue "Digital Geographies and the City" edited by Wen Lin (Newcastle University, UK).

(C) 2020 by the author; licensee Cogitatio (Lisbon, Portugal). This article is licensed under a Creative Commons Attribution 4.0 International License (CC BY).

\section{Introduction}

At around 10pm on a typically steamy April evening in Haikou, People's Republic of China (PRC), myself, my partner Jerry and our friends Xiao Long, Ah Fan and Li Pei sat around a table amongst the mobile food stalls that gather every evening in a street opposite the South Gate of Hainan University. It had become a tradition that a couple of times a week we would meet at the pool in my nearby apartment complex, swim for a while, and then eat at the South Gate food stalls. We all lived within a 300 -metre radius of where we were sitting. We knew this not because we had told each other but because we had come to know each other through Blued, a location-aware mobile app used by men in the PRC to find sex, friendship and romance with other nearby men. The food stalls were at their peak of business; students and local residents sat squeezed, shoulder to shoulder, on plastic stools around fold-away tables while motorbike taxis cut a path through the throng with their honk- ing horns. We were waiting an unusually long time for our food to arrive and a lull in our conversation turned Xiao Long's attention to his phone: "Fuck! Look how many gays there are here!" he exclaimed, as he turned his phone to Ah Fan, Blued open. Intrigued, the rest of us followed suit, picking up our phones and opening Blued to survey the plethora of nearby men: "This guy's cute, right?," Xiao Long continued, "he's only 10 metres away, he must be here somewhere." The hunt was on for username: Dream Big. We each began to scan the crowd, our attention so focused that the eventual arrival of our food garnered only a distracted "thanks." "Is that him?" asked Li Pei, as he raised his eyebrows and glanced at a point in the crowd behind my left shoulder. We followed Li Pei's gaze to where a man in his early twenties sat at a table with a group of women. Dream Big glared back at us with a look of both panic and excitement, he then promptly placed his phone face-down on the table and returned to his conversation with the women around him. 
When men who desire men use digital technologies to find one another, their experiences of urban spaces are altered, and spaces may be reproduced as sites of significance in their sexual geographies. As in the above vignette, social relationships can be established on the basis of proximity in offline spaces and those spaces of proximity can be transformed; a 'nearby' swimming pool becomes a meeting place for men who desire men and a crowded night market becomes their hunting ground. Such spatial reformulations are facilitated by digital technologies that layer new knowledge onto offline spaces. Yet, these dynamics are not determined by technologies alone. Rather, they unfold as an interplay of technological, social, political and economic forces (Wajcman, 2010). In this article, I explore how digital technologies, especially the location-aware dating app Blued, are used by men who desire men in Haikou. I argue that these technologies shape the ways in which users imagine and engage with the city and, by mapping the presence of other men who desire men, foster the production of particular sites of sexual significance. Attending to the wider contexts within which these dynamics are located, I situated the digitally mediated production of these spaces within the political and social realities of nonheterosexual lives in Haikou and the PRC more broadly. By offering insights into a non-Western and 'provincial' setting, this article advances the field of research into interrelations of space, sexuality and digital technology, which has been dominated by research on major urban centres in European and Anglophone contexts.

I draw on 12 months of ethnographic fieldwork in Haikou (2015-2016), including 12 semi-structured interviews with men who desire men aged 24-63 and participation in their everyday social practices. This time spent in Haikou was part of an 18-month period of fieldwork across Hainan. A total of 30 interviews were conducted with men aged 18-63 across Haikou, Sanya (a city in the south of Hainan) and various smaller cities, towns and rural sites. This wider research sought to understand how men who desire men in Hainan negotiate understandings of themselves and their lives in relation to a range of everyday social and material contexts, amongst which digital technologies were key. While the primary focus of this article is on Haikou, I also draw on this broader dataset and include examples from other cities in Hainan.

In this article, both I and my interlocutors use a range of terms to refer to same-sex desires and identities, including 'non-heterosexual,' 'gay,' 'tongzhi' (literally 'comrade'; see Bao, 2018, pp. 28-32, for discussion) and 'homosexual.' I most often use the term 'men who desire men.' This is in avoidance of the assumption of stable identities inherent in the terms 'gay' and 'tongzhi,' the pathologising under-tones of 'homosexual' and the reduction of social experience to a sex act embodied in the more common term 'men who have sex with men.' These issues of terminology are complex and contested in cross-cultural sexualities research (see Boellstorff, 2007, for discussion).

\section{Research Contexts}

\subsection{Haikou}

Haikou is the provincial capital of Hainan, an island province of the PRC which lies in the Gulf of Tonkin, $19 \mathrm{~km}$ off the southern coast of the PRC mainland. Haikou is the political and economic centre of Hainan and has a population 1.9 million (Statistical Bureau of Hainan Province, 2017). While this makes it the largest city on the island, Haikou is diminutive by comparison to most other provincial capitals in the PRC. Along with Hainan more generally, Haikou has long been considered a peripheral backwater in both the state and popular geographic imagination (Feng, 2005). It is classified as a 'third tier city' in the PRC's four tier system of ranking cities by population size, economic output, infrastructure and political and cultural influence (Ministry of Commerce of the People's Republic of China, 2020). In 2016, when this research was conducted, average disposable income in Haikou was RMB 30,775 (Statistical Bureau of Hainan Province, 2017). This was below the national average of $33,616 \mathrm{RMB}$ for urban areas and well below the average of RMB 50,883 in the PRC's 'first tier cities': Shanghai, Beijing, Guangzhou and Shenzhen (National Bureau of Statistics of China, 2017).

In Haikou, as elsewhere in the PRC, limited public discourses on sexual diversity and pervasive Confucian cultural norms that valorise heterosexual reproduction mean that very few men who desire men make their sexuality known beyond social networks of other men who desire men. Anecdotal accounts from older men in Haikou suggest that non-heterosexual spaces first emerged in the city in the mid-1990s when men began meeting on a particular pedestrian bridge. Later, an alternative meeting place was established in a nearby park, where men continue to meet today. Haikou's first gay bars are said to have appeared in the mid-2000s and, since 2007, there has always been at least one gay bar in the city. Most bars have been short-lived and a total of five gay bars have opened and closed at various locations over the past 13 years. Haikou's current gay bar has been in operation since 2013, making it the longest surviving. Since 2008, infrequent social gatherings have been organised by informal 'LGBT' community groups and AIDS prevention organisation targeting men who have sex with men.

\subsection{Blued}

Despite the 1997 removal of legal stipulations that rendered same-sex sexual activities punishable under the crime of 'hooliganism' and the 2001 de-classification of 'homosexuality' as a mental illness ( $\mathrm{Wu}, 2003)$, state censorship continues to limit mainstream media representations of gender and sexuality to cisgendered, heterosexual relations and activist organisations are closely monitored by the state (Bao, 2020). In this context, 
online platforms operate as privileged sites for the representation of sexual diversity and the formation of nonheterosexual social networks and identities (Ho, 2010). Since the early 2010s, mobile, locative dating apps have become one of the primary ways in which men who desire men in the PRC find one another, these include apps such as Grindr, Jack'd and Blued (Wang, 2018; Zhao, Sui, \& Li, 2017). Such technologies use global positioning software to make users aware of their offline proximity to one another. In a sociopolitical context in which nonheterosexual lives are largely invisible in public spaces, these technologies play an important, even revolutionary, role in the everyday lives of men who desire men in the PRC, enabling social and sexual intimacies otherwise largely curtailed by pervasive heteronormativity (Cummings, 2020).

Launched in 2012, Blued has become the most widely used non-heterosexual locative dating app in the PRC. As of 2020, Blued boasts 40 million users, 28 million of whom are located in the PRC (Blued, 2020). The app's success in the face of state censorship and regulation in the PRC is, in part, due to its prohibition of sexually explicit imagery and language and its self-branding as a tool to support AIDS prevention work (Lopez, 2014). The app offers a range of social media functions, including personal profiles, private chat and the ability to video livestream. Its primary function and main draw, however, is its use of global positioning technology to present users on a grid interface in relation to their distance from one another in offline space (Figure 1).

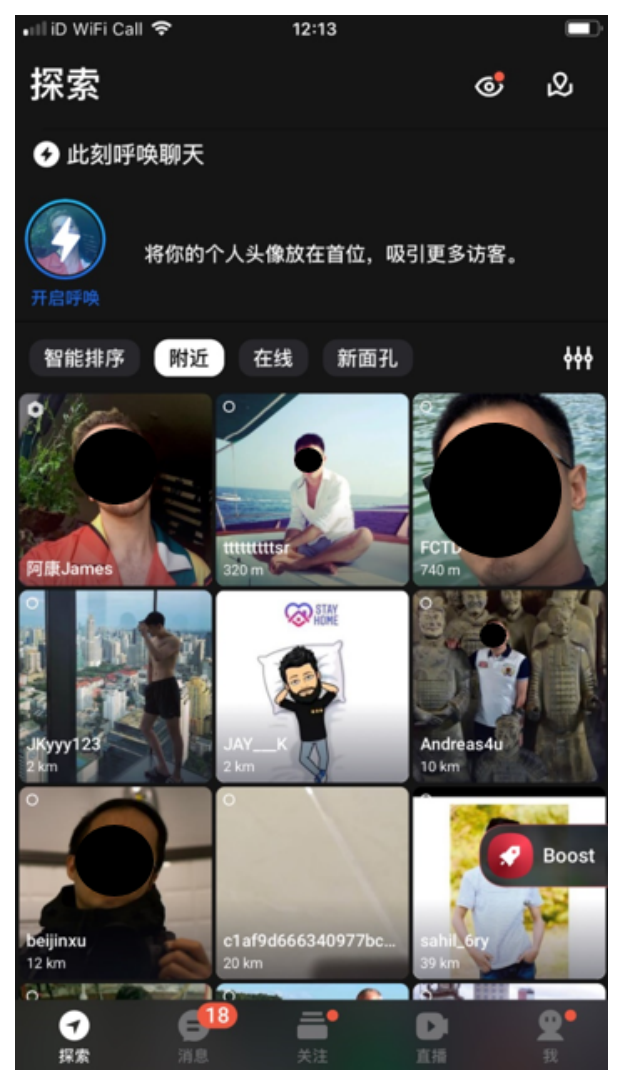

Figure 1. Blued interface. Source: Author.

\section{Sex and the Digital City}

In what has been deemed a 'digital turn' in geography, scholars have illuminated the capacities of global positioning, mobile and data gathering technologies to transform the ways in which cities are experienced (Ash, Kitchin, \& Leszczynski, 2018). The ubiquity of such technologies in contemporary urban environments has led some to conclude that cities now wear a 'digital skin' in the form of networks of technologies that gather and share information on the daily to-and-fro of urban life (Rabari \& Storper, 2015). As such, cities exist not only in their physical structures and the movements of goods, people and capital but also in ever-increasing volumes of digitally captured and shared knowledge (Couldry \& Hepp, 2017). Access to this knowledge is unevenly distributed between governments, businesses, individuals and distinct social groups variously creating and connecting to diverse digital networks (de Souza e Silva \& Firth, 2012). Cities, therefore, do not wear a digital skin but multiple skins: They become vastly different spaces depending upon one's access to, and position within, digital networks of knowledge (Foth, Brynskov, \& Ojala, 2016).

Geographers of sexuality have explored the specific significance of digital technologies and their mediation of offline spaces for non-heterosexual people (Miles, 2018; Mowlabocus, 2010; Nash \& Gorman-Murray, 2019). The Internet has long enabled marginalised sexual groups to access information, build communities and experience social and sexual intimacies (Campbell, 2004; Döring, 2009; Gudelunas, 2012; Pullen \& Cooper, 2010). As such, digital technologies and connectivity have been seen to have reduced the role of gay bars and cruising sites as vital hubs for urban non-heterosexual communities; the advent of mobile same-sex dating apps has further dislocated non-heterosexual communities and identities from fixed spaces (Miles, 2017; Nash, 2012). At the same time, however, scholars have drawn attention to the ways in which digital technologies may foster less the deterritorialisation of non-heterosexual communities and identities than the emergence of new and complex relationships between space, technology and sexuality (Bonner-Thompson, 2017; van Doorn, 2011). Researchers have explored how mobile, location-aware dating apps can imbue any space with the possibility of intimate non-heterosexual connection, rather than those spaces explicitly marked as sexually significant (Stempfhuber \& Liegl, 2016). This has been seen to challenge heteronormativity by facilitating same-sex connections within everyday spaces otherwise characterised by naturalised assumptions of heterosexuality (Roth, 2014). Cockayne and Richardson (2017) have theorised such dynamics as the 'queering of code/space'-a technologically mediated reproduction of spaces that makes possible the transgression of regulatory sexual norms.

These debates on the nature of relationships between space, digital technologies and contempo- 
rary sexualities have largely focused on European and Anglophone contexts (Szulc, 2014). Literature on nonheterosexual lives in diverse locations beyond the 'West' has documented the vital role that the Internet and digital technologies play in identity construction and political organisation (Das, 2019; Gorkemli, 2012). This is especially the case in contexts, such as the PRC (Bao, 2020), where state authoritarianism and conservative cultural mores maintain pervasive heteronormativity. However, less attention has been paid to what these technologies mean for the everyday spatiality of nonheterosexual lives in diverse sociocultural and political settings. Broaching these themes, Choy (2018) has noted how the location-aware mobile dating app Butterfly allows Hong Kong lesbians to escape the heteronormative ordering of their everyday lives and find one another as they move through the city. In his work on LGBT organisations in Singapore, Luger (2019) argues that activists circumvent the prohibition of sexual rightsthemed public events by gathering in public spaces while only acknowledging the purpose of their gathering in online settings; they thereby lay claim to public space without risking state interference.

Further, research into geographies of sexuality more broadly, both within and beyond the 'West,' has tended to privilege national capitals and major economic, political and cultural centres (Stone, 2018). This scholarly orientation reflects and perpetuates popular perceptions of such sites as sexually liberal and progressive in contrast to smaller, 'ordinary' cities, towns and rural areas, imagined as sexually conservative. Halberstam (2005) has termed such geo-sexual imaginaries 'metronormativity' and has highlighted the necessity of attention to non-heterosexual lives across diverse geographic settings. Importantly, as critical geographers have argued, spatial categories of the metropole and the margin, the urban and the rural, or the city, the town and the village, are not independent of one other but are articulated relationally (Massey, 1994). As such, understanding relationships between sexuality and urban space requires attention to co-constitutive discourses of 'the urban' and 'the rural' and their imagination as distinct sexual spaces (Detamore, 2013; Herring, 2007; Johnson, Gilley, \& Gray, 2016).

In the following sections, I explore a range of ways in which digital technologies shape the spatial imaginations and experiences of men who desire men in Haikou and Hainan more widely. In doing so, I contribute to the above literatures, offering new insights into the interrelations of space, sexuality and digital technologies in a non-Western and 'provincial' setting. I begin by addressing the relational construction of spaces as 'urban/rural' vis-à-vis the visible presence and absence of men on Blued. I then turn to accounts of the impact of digital technologies on 'traditional' non-heterosexual spaces (gay bars and cruising areas). Finally, I suggest that Blued has facilitated the emergence of new non-heterosexual spaces in Haikou that exist only in the interstices of the online and the offline. Across these sections, I ague that digital technologies disrupt, redefine and multiply urban spaces in Hainan and offer men who desire men new ways of seeing and experiencing the urban environment.

\section{Mediating 'the Urban' and 'the Rural' as Sexual Spaces}

While particular urban spaces have their tangible materiality, 'the urban' itself is more difficult to grasp. As it is figured in everyday discourse, the urban is not an objective geographic demarcation but an imagined site suspended in webs of meaning and representation that concern who lives, and what life is like, in different locations (Massey, 1994). For men who desire men in Hainan, 'the urban' was often articulated against 'the rural' and the imagination of both spaces was mediated by digital technologies.

Many participants in urban settings spoke of an urban/rural digital divide. On the one hand, the uneven geographic distribution of Internet access and digital technologies has been a facet of wider socioeconomic inequalities between urban and rural settings in the PRC (Fong, 2009). On the other hand, such invocations of a digital divide are also one of the key ways in which 'the urban' and 'the rural' come to be imagined as distinct spaces (Graham, 2011). This was evident in participants' reflections on the lives of rural men who desire men. 29-year-old Ah Gang and 26-year-old Xiao Pang both lived in Wuzhishan City in central Hainan. They discussed how a digital divide may impact men in "far off villages":

Ah Gang: Last time, we were talking about what it would be like for someone in one of those far off villages.

Xiao Pang: Without Internet, so far away.

Ah Gang: In those villages, they don't have Internet, they come into the city to go to school and find out that they are gay. There was someone like this who we met up with...he realised that he liked men while he was still in his village, that's quite a feat, in that kind of village.

\section{Xiao Pang: There would be no one to tell him.}

From their own urban location, Ah Gang and Xiao Pang imagined that a defining feature of non-heterosexual lives in rural settings is a lack of access to the Internet. This was seen to leave men in "far off villages" isolated from information that would enable them to recognise themselves as "gay," to make sense of their sexual desires and claim belonging to a collective identity category. Here, 'the rural' is seen as isolated, not only in terms of geographic but also informatic and digital distance from the urban. In this geo-digital-sexual landscape, Internet-enabled access to certain forms of sexual knowledge becomes a definitional quality of 'the urban.' 
As such, it appears that if rural men are to "find out that they are gay," they must "come into the city" and connect to the Internet.

Distinctions between 'the urban' and 'the rural' were made not only in terms of Internet access but also Internet and digital literacy and its implications for the ways men who desire men connect with, or remain isolated from, one another. 54-year-old Ah Zheng lived in Sanya, the second largest city in Hainan. He contrasted digitally literate men in urban settings with men in "the countryside," whose apparent inability to use digital technologies left them excluded from non-heterosexual social networks. He described these men as 'anchang,' a derogatory term used to comedic effect by men who desire men that can be literally translated as 'hidden whores':

There are a lot of anchang who don't come and hang out, those in the countryside...anchang are outside and they don't come into contact with people like us....It's hard for them to get the information, it's backward, it's backward in the countryside, and they live there so they don't get this kind of information, these softwares; they don't understand how to use these kinds of apps.

Ah Zheng's definition of 'the countryside' as 'backwards' was premised on the apparent digital illiteracy of rural men who desire men. Digital literacy, here, comes to serve as a standard that informs the recognition of spaces as 'rural' or 'urban' and as 'backward' or 'progressive.' Unable to "get this kind of information" and "use these kinds of apps," the 'anchang' that Ah Zheng describes are seen as isolated from social networks of non-heterosexual men; as he put it: "They don't come into contact with people like us." Through the imagination of a digitally illiterate and 'backward' countryside, occupied by isolated men, the "people like us" to which Ah Zheng refers implicitly come to signify digitally literate, progressive, urban, and connect men who desire men.

Such spatial categorisations vis-à-vis digital technologies and practices are intensified by way in which Blued serves to map the presence of other men who desire men. As Blued renders perceptible the offline proximity of other users, it offers a visualisation of the number of users within a certain geographic radius. For some participants, the relative 'profusion' and 'scarcity' of Blued users informed distinctions they made between spaces at various scales. 45 -year-old Lu Ge, who lived in Sanya, exemplified these dynamics as he reflected on using Blued to look for other men outside of Hainan's largest cities: "When we go down to the counties, smaller places, like Wuzhishan, somewhere like that, you won't see a single person all night, there's no one on that app [Blued]! [Lu Ge laughs] It's like there's no one there."

Here, the presence and absence of other men "on that app" within particular geographic demarcations is a central feature in relation to which such demarcations are themselves articulated. For Lu Ge, the apparent paucity of men on Blued in "the counties" and "smaller places" was a definitional quality of those spaces themselves; it became part of the ways in which such spaces are categorised as "somewhere like that"' and experienced as 'big' or 'small,' 'urban' or 'rural.'

These accounts from men who desire men in Hainan show how 'the urban' and 'the rural' are articulated and experienced in relation to digital technologies. It is important to note, however, that these assumptions of limited Internet access and literacy in Hainan's rural areas contrast with the experiences of participants who either lived or grew up in villages and smaller towns. Speaking of his home village in Chengmai County, 23-year-old Ah Run noted: "Our gay scene back there is like this, I found that softwares are just like gay bars for us."

In this sense, the above accounts may not represent an actually existing digital divide between 'the urban' and 'the rural.' Rather, the conflation of urbanity with Internet access and sexual connectivity appears to be a discursive strategy and form of metronormativity through which urban men who desire men frame themselves and their spatial locations as 'modern' and 'progressive' in contrast spaces imagined as digitally and sexually 'backward.'

\section{Digital Technologies and 'Traditional' Non-Heterosexual Spaces in Haikou}

Regardless of whether the above-discussed 'digital divides' are a discursive tool or a material and experienced reality, each of the above excerpts points to the central role that digital technologies played in participants' everyday social and sexual interactions. As noted earlier, research conducted in 'Western' cities has suggested that the rise of digital media has reduced the social significance of 'traditional' non-heterosexual meeting places, such as gay bars and cruising sites (Nash, 2012). Many participants suggested that this is also the case in Haikou.

Many participants similarly felt that the ease with which other men could be found and contacted online meant that fixed, offline non-heterosexual spaces were no longer necessary. 18-year-old Xiao Qiao lived in a small town in Chengmai Country in northern Hainan. He often made the one-hour journey by bus into Haikou to socialise at the city's gay bar. Despite this regular patronage, when asked what he felt the impact on his life would be if Haikou's gay bar were to close down, he replied:

I don't think it would have an impact...the main reason that you go to a gay bar is, like I was just saying, to go looking for friends....But now you can meet people entirely through Blued, arrange on Blued to meet and go singing, get a karaoke booth, meet up and have fun. This is another form of gay bar, even 
though in name it isn't a gay bar, but if you arrange to meet with some people, go there for fun, isn't it exactly the same as a gay bar? If, for example, there was no Internet, I think that gay bars would allow tongzhi to communicate, but now the Internet is everywhere, so, for us, gay bars are just somewhere you go for a bit of excitement.

For Xiao Qiao, the ability to "meet people entirely through Blued" had not rendered Haikou's gay bar irrelevant, however, it had fundamentally changed its meaning and function. Bars were seen to have once been vital sites at which to "go looking for friends" and build communities. With these functions now served by digital technologies, bars become simply "somewhere you go for a bit of excitement." Xiao Qiao also points to the ways in which digital technologies enable the creation of new and temporary non-heterosexual spaces. In contrast to the fixity of a gay bar, as men find one another online and arrange to meet in offline spaces, the sexuality of those spaces is temporarily transformed such that "a karaoke booth" can become "another form of gay bar." These processes of temporary, fluid and partial redefinition of otherwise heterosexual spaces are explored in more detail in the following section.

For Xiao Qiao, the excitement that Haikou's gay bar offered was enough to ensure that he continued to visit. Several participants made similar comments and felt that gay bars still provided a fun and safe space within which they could experience social belonging and relax without the regulatory surveillance they felt in heterosexual spaces. Others were less certain that gay bars remained socially relevant in the face of digital technologies and connectivity. As such, digital technologies were not only seen to shape the meanings and social function of gay bars in Haikou but were recognised as a threat to their sustainability. As Ah Gang commented:

In the past, in Haikou, there wasn't just that one gay bar, [there were] three or four. But later, for economic reasons, they shutdown. Back then there weren't softwares; those few gay bars emerged along with online chatrooms, offline they would go to those few bars. But now there's only one bar left. As softwares have developed people don't want to go there to meet other people anymore.

The economic struggles, and resultant impermanence, of gay bars in Haikou are not solely the consequence of their replacement by digital technologies. In the 'first tier cities' of Beijing, Shanghai, Guangzhou and Shenzhen, larger populations, higher wages and a steady stream of domestic and international visitors ensure the economic viability of a certain number of gay bars and allow for elaborate decoration and a varied schedule of entertainment activities (Bao, 2020). By contrast, gay bars in Haikou are dependent upon a comparatively small local market with limited spending power and wary of visiting explicitly non-heterosexual spaces 'so close to home' for fear being seen by family members or colleagues. These economic and social constraints mean that gay bars in Haikou have limited cash flow, basic decoration and have historically been located in low-rent sites in the city centre. As such, they struggle to attract already hesitant customers and many participants voiced their dissatisfaction with the environment in Haikou's gay bars. It is under these already fraught economic and social conditions that the sustainability of gay bars in Haikou is threatened by further reductions in the numbers of patrons due to the ease and anonymity of meeting men online.

Interestingly, as Ah Gang notes above, in Haikou, "gay bars emerged along with online chatrooms." This parallel emergence of online and offline spaces within which non-heterosexual men meet contrasts with 'Western' contexts in which gay bars and other offline meeting places in urban centres predated widespread use of the Internet by decades (Bell \& Binnie, 2004). The relationship between 'traditional' non-heterosexual spaces and digital technologies in Haikou is therefore more complex than a matter of the former being replaced by the latter. This was also the case for the cruising site that exists in a park in Haikou, which, as noted earlier, was established in the mid-1990s. As 42-year-old Yefeng recalled:

There was a hotel by the side of the park with an Internet cafe on the ground floor; it was the first place in Haikou where you could get online. So, there were people who would go there to go online and look for other tongzhi. When they found someone, they would arrange to meet in the park....So, like this, it became a tongzhi meeting place.

As scholars have argued, the development of nonheterosexual identities in the PRC is intimately linked to the proliferation of digital information and communication technologies (Cummings, 2020; Ho, 2010). It appears that the development of 'traditional' nonheterosexual spaces in Haikou, and likely elsewhere in the PRC, is similarly caught-up with these technologies, raising the question of whether these offline sites should be considered 'traditional' at all.

Even in recent years, in which mobile smartphones and dating apps have decoupled access to both the Internet and to other men who desire men from fixed locations, these same technologies may also be involved in the production of 'traditional,' fixed non-heterosexual spaces. This is exemplified in the case of Sanya's current gay bar Tianchi. The bar was established in 2012, the same year that Blued was released. As the new app sought routes to access its intended market, Blued offered to pay gay bars in the PRC to advertise the app. Tianchi took advantage of this and used money from Blued to install a large, illuminated sign by its entrance (Figure 2). In return, the sign featured Blued's name and logo. This sign adorned Tianchi's doorway until 2015, when the bar relocated. The sign was so effective that, 


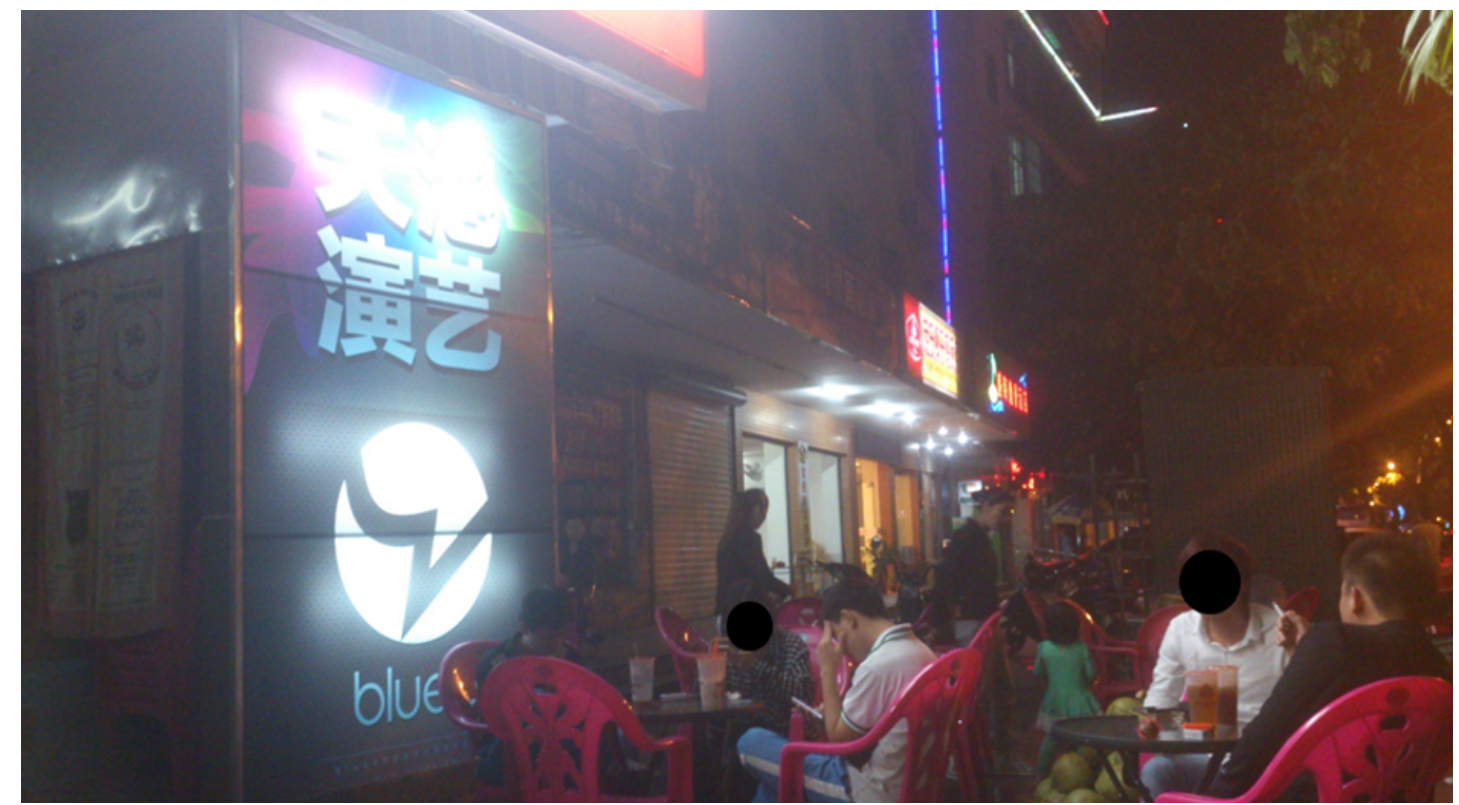

Figure 2. Blued sign outside Tianchi. Source: Author.

before the app became widely known and used, some men in Sanya believed that it was in fact the bar itself that was named 'Blued.' For Tianchi, a further benefit of this sign and its inclusion of Blued's logo was the way in which it tacitly announced the presence of a gay bar without the need for explicit terms to refer to sexuality. In the political and social climate of the PRC, and Hainan in particular, the use of terms such as 'gay,' 'tongzhi' or 'homosexual' in Tianchi's publicly visible signage could risk attracting unwanted attention from the general public and the authorities. It would also deter local non-heterosexual people from visiting the bar for fear of being seen entering. In this context, the illuminated logo of an app catering to men who desire men turned Tianchi into a visible non-heterosexual space while ensuring that it was visible as such only to those familiar with Blued.

\section{Locative Technology and the Queering of Public Space in Haikou}

As the above discussion shows, the digital is often perceived as a threat to materially situated, offline non-heterosexual spaces, and yet it is simultaneously involved in the production, redefinition and recognition of such spaces. In this sense, the digital and the material, or the online and the offline, are not opposed to, but rather intimately intertwined with, one another. This is nowhere clearer than when men who desire men use Blued to map one another within offline spaces and their understandings of those spaces are radically changed.

In the context of pervasive heteronormativity in the PRC, almost all participants discussed the role of early Internet technologies, such as websites and chatrooms, in facilitating their first access to sexual discourses beyond heterosexuality and in enabling their first con- tact with other men who desire men. With the move to locative technology in the form of Blued, these online forms of knowledge and intimacy can be mobilised within, and mapped onto, offline spaces. 26-year-old Xiao Lei exemplified these dynamics as he recalled the first time that he used the Internet to access diverse sexual discourses:

Xiao Lei: [My classmate] asked me to go with him to an Internet cafe to log on to this website. So, slowly, we learned that, like: 'Oh, this is gay.' At first, it was very difficult; I felt like I was a pervert....Before I found out that there were so many people like this all around me, I thought that there was only me, I hadn't found out that anyone around you might potentially be someone in this scene.....t's been a long time since I've logged on to that website.

James: Why is that?

Xiao Lei: Because now there is Blued [Xiao Lei laughs]....You can use Blued to chat on your phone; now you can see who's around you. It's a lot more convenient than using a computer. If you're out with your friends and you're bored, you can have a look who's around you, see what handsome guys are in the area!

Xiao Lei's early access to diverse sexual discourses online led to his realisation that he was neither "a pervert" nor the only person "like this." Knowing that "anyone around you might potentially be someone in this scene" was fundamental in Xiao Lei normalisation and acceptance of his desires for men. With the arrival of Blued, this 'potential' presence of other men who desire men is transformed into a perceptible reality, as other users become visible within one's immediate offline 'vicinity.' Echoing Xiao Lei, 
for 24-year-old Dingfeng, Blued offered access to a "hidden world" beneath the heterosexual surface of everyday spaces:

These apps give us a way of knowing that this hidden world exists; you don't feel so lonely; it's like they shine a light onto this hidden world and let you sense it; they let you know that it exists.

In these accounts, Blued functions as a lens through which offline spaces and their occupants become visible in new ways. This not only shapes how men who desire men in Haikou feel about themselves, others and the spaces they share but also gives rise to new spatial-social practices which, in turn, establish new non-heterosexual spaces in the city.

As seen in discussions of 'the urban' and 'the rural,' Blued makes visible one's proximity to, and the density of, other users across multiple spatial scales. In Haikou, this has led to the production of certain urban spaces that are understood as densely populated by men who desire men. One such place is the men's wear section on the fifth floor of a particular shopping centre on the city's bustling Jiefang West Road. I was first taken there by a friend who had heard that there were "a lot of gays there." This rumour was confirmed upon opening Blued and finding other users just metres away. This densely packed, windowless warren of string vests and skinny jeans subsequently became a site we would regularly visit. With our phones in our hands, we would spend our evenings feigning interest in clothes and shoes, all the while casting glances at the shop owners and other shoppers, trying our best to recognise these men as those that Blued told us were just metres away. Seeing other men, phones in hands, we would assume they were doing the same and, on occasion, a knowing smile or the familiar sound of an incoming Blued message would tell us that, indeed, they were.

Other such spaces exist in Haikou: Another popular shopping centre in the more affluent Guomao area; Hainan University campus, with its heightened collocations of young men and, unsurprisingly, the stretch of road along which both Haikou's gay bar and cruising area are located within 300 metres of one another. Each of these are spaces within which Blued makes visible elevated densities of users and, as such, the expectation that "anyone around you might potentially be someone in this scene" becomes part of the way in which these spaces are constructed and experienced by men who desire men. As men tell one another that "there are lot of gays there" and see this confirmed via Blued, these spaces become landmarks in shared sexual geographies of the city. The extent to which these new non-heterosexual spaces become widely recognised as such requires reliably high densities of Blued users such that this becomes a definitional feature of these spaces. It also depends upon the widespread sharing of this knowledge such that it becomes part of the cultural repertoire of local non-heterosexual communities. Such spaces are therefore established only slowly and infrequently.

Much more often, spaces are temporarily redefined, as Blued makes visible the surprising presence of another user at close proximity. This was the case in the vignette with which this article opened, when a night market was temporarily transformed into a landscape across which men who desire men search for one another in the hope of establishing social and sexual relationships. Such temporary subversions of the heteronormative order of spaces happen countless times whenever a Blued user spots 'a cute guy nearby' and their immediate surroundings suddenly take on new sexual significance. Yet, these subversions leave no lasting mark upon the spaces within which they occur. The social and political significance of such subversions is therefore ambiguous; they are, at once, radical challenges to the sexual order of public spaces under pervasive heteronormativity and fleeting moments of excitement that are soon forgotten.

Participants largely celebrated these new possibilities for men who desire men to see and engage with one another in public spaces. Yet, there were instances in which the potential to be identified as non-heterosexual caused anxiety. These concerns often surfaced in discussions of Blued users who did not include a photo of themselves on their profiles and were, therefore, able to recognise other users in offline spaces but did not render themselves recognisable in the same way. As 24-year old Liang Zongwei recounted:

Liang Zongwei: When I'm out, I might receive a message that says "hey, I've just seen you at such-andsuch a place." I just think "whatever." But I have a friend who gets very nervous, he'll say, "oh no, I've been recognised!"

James: What is it that your friend is afraid of?

Liang Zongwei: There are people who don't put their own photos on there, they will threaten you. I have a friend who has been threatened. Someone threatened to expose him in his workplace; it was one of his colleagues, you know...he said he had to do what they told him.

As Liang Zongwei illustrates, uneven relations of recognisability across online and offline spaces can leave men who desire men open to blackmail. In the PRC, the exposure of non-normative sexuality within family and professional settings can have serious repercussions, including the termination of these relationships. As such, caution must be taken in claiming the liberatory potential of Blued to transform public spaces into sites in which men who desire men are visible to one another. While this may challenge the enforced invisibility of nonheterosexual men in public space, for some men, invisibility was a desirable form of protection from homophobic violence. In contrast to joyous accounts of digitally medi- 
ated public visibility, for men such as Liang Zongwei's friend, Blued's mapping of users within offline settings turned the streets of Haikou into spaces of risk and fear.

\section{Conclusion}

Geographers of sexuality have concluded that "the Internet, new media and mobile apps, appear to be fomenting a new 'sexual revolution,' one that is rewriting how we understand what our bodies can 'do' and how we comprehend ourselves as sexual beings" (Nash \& Gorman-Murray, 2016, p. 353). As this article has shown, these technologies are also rewriting the spaces we occupy and how we comprehend those with whom we are co-present. These digitally mediated shifts in the sexual ordering of spaces are not only occurring in the 'Western' and/or major-city spaces that have been the focus of much existing work. They are also unfolding in 'ordinary' cities the world over and are shaped by specific social, economic and political forces therein. In Haikou, and Hainan more widely, the use of digital technologies by men who desire men is shaping what it means for a space to be seen as 'urban' or 'rural' and the imagined nature of sexual cultures therein. As elsewhere, the rise of digital technologies has changed the social significance of 'traditional' non-heterosexual spaces, such as gay bars and cruising sites. Operating in an already unfavourable economic and social context, this may threaten the sustainability of such spaces in Haikou; yet, there are also instances in which the digital and the 'traditional' have emerged as intertwined. These capacities of digital technologies to shape urban spaces are strikingly clear in the emergence of new non-heterosexual spaces in Haikou that exist in the interstices of the online and the offline as urban densities of men who desire men are made visible on Blued. Such disruptions of otherwise heterosexual spaces are cause for celebration as they open-up possibilities for men who desire men to claim public space. Yet, their political significance is limited by their often fleeting and individual nature and the heightened risks of homophobic violence that come with visibility in public space.

This article has sought to advance research into urban geographies of sexuality in the digital age by looking at the experiences of men who desire men in a non-Western and 'ordinary' city. While this article has explored digitally mediated discursive constructions of 'the rural,' further research is needed into how digital technologies are shaping the lives and spatial experiences of men in rural areas. Non-heterosexual women are also notably absent from both this article and the spaces it has explored, raising questions of how and where non-heterosexual women are finding one another and what role digital technologies play in these processes. Finally, the dynamics discussed in this article are premised on assumptions that digital, locative technologies offer accurate representations of the offline, physical presence of other users. Further research should consider the roles that technological failure and experiences of disjunct between the online and the offline may play in the digitally mediate production and disruption of urban space.

\section{Acknowledgments}

This work was supported by the Economic and Social Research Council, grant number ES/J500082/1.

\section{Conflict of Interests}

The author declares no conflict of interests.

\section{References}

Ash, J., Kitchin, R., \& Leszczynski, A. (2018). Digital turn, digital geographies? Progress in Human Geography, 42(1), 25-43.

Bao, H. (2018). Queer commerades: Gay identity and tongzhi activist in postsocialist China. Copenhagen: NISA Press.

Bao, H. (2020). Queer china: Lesbian and gay literature and visual culture under postsocialism. Abingdon: Routledge.

Bell, D., \& Binnie, J. (2004). Authenticating queer space: Citizenship, urbanism and governance. Urban Studies, 41(9), 1807-1820.

Boellstorff, T. (2007). Queer studies in the house of anthropology. Annual Review of Anthropology, 36, 17-35.

Bonner-Thompson, C. (2017). "The meat market": Production and regulation of masculinities on the Grindr grid in Newcastle-upon-Tyne, UK. Gender, Place \& Culture: A Journal of Feminist Geography, 24(11), 1611-1625.

Campbell, J. (2004). Getting it on online: Cyberspace, gay male sexuality, and embodied identity. New York, NY: Harrington Park Press.

Choy, C. (2018). Smartphone apps as cosituated closets: A lesbian app, public/private spaces, mobile intimacy, and collapsing contexts. Mobile Media and Communication, 6(1), 88-107.

Cockayne, D., \& Richardson, L. (2017). Queering code/space: The co-production of sociosexual codes and digital technologies. Gender, Place \& Culture, 24(11), 1642-1658.

Couldry, N., \& Hepp, A. (2017). The mediated construction of reality. Cambridge: Polity Press.

Cummings, J. (2020). 'Now you can see who's around you': Negotiating and regulating gay intimacies on mobile media in the People's Republic of China. In J. Cabañes \& C. Uy-Tioco (Eds.), Mobile media and social intimacies in Asia: Reconfiguring local ties and enacting global relationships (pp. 15-30). Chennai: Springer.

Das, V. (2019). Dating applications, intimacy, and cosmopolitan desire in India. In A. Punathambekar \& 
S. Mohan (Eds.), Global digital cultures: Perspectives from South Asia (pp. 125-141). Ann Arbor, MI: University of Michigan Press.

de Souza e Silva, A., \& Firth, J. (2012). Mobile interfaces in public space: Locational privacy, control and urban sociality. New York, NY: Routledge.

Detamore, M. (2013). Queering the hollow: Space, place, and rural queerness. In A. Gorman-Murray, B. Pini, \& L. Bryant (Eds.), Sexuality, rurality, and geography (pp. 81-94), Lanham, MD: Lexington.

Döring, N. (2009). The Internet's impact on sexuality: A critical review of 15 years of research. Computers in Human Behaviour, 25(5), 1089-1101.

Feng, C. (2005). From barrooms to teahouses: Commercial nightlife in Hainan since 1988. In J. Wang (Ed.), Locating China: Space, place, and popular culture (pp. 133-149). Oxon: Routledge.

Fong, M. (2009). Digital divide between urban and rural regions in China. The Electronic Journal of Information Systems in Developing Countries, 36(1), 1-12.

Foth, M., Brynskov, M., \& Ojala, T. (2016). Preface. In M. Foth, M. Brynskov, \& T. Ojala (Eds.), Citizen's right to the digital city: Urban interfaces, activism, and placemaking (pp. v-vii). Singapore: Springer.

Gorkemli, S. (2012). "Coming out of the Internet": Lesbian and gay activism and the Internet as a "digital closet" in Turkey. Journal of Middle East Women's Studies, 8(3), 63-88.

Graham, M. (2011). Time machines and virtual portals: The spatialities of the digital divide. Progress in Development Studies, 11(3), 211-227.

Gudelunas, D. (2012). "There's an app for that": The uses and gratifications of online social networks for gay men. Sexuality \& Culture, 16(4), 347-365.

Halberstam, J. (2005). In a queer time and palce: Transgender bodies and subcultural lives. New York, NY: New York University Press.

Herring, S. (2007). Out of the closets, into the woods: RFD, country women, and the post-Stonewall emergence of queer anti-urbanism. American Quarterly, 59(2), 341-372.

Ho, L. (2010). Gay and lesbian subculture in urban China. Abingdon: Routledge.

Johnson, C., Gilley, B., \& Gray, M. (2016). Introduction. In M. Gray, C. Johnson, \& B. Gilley (Eds.), Queering the countryside: New frontiers in rural queer studies (pp. 1-22). New York, NY: New York University Press.

Lopez, T. (2014, December 2). Chinese government hooks up with gay dating app to fight HIV. Slate. Retrieved from https://slate.com/humaninterest/2014/12/chinese-government-works-withgay-hookup-app-blued-to-fight-hiv.html

Luger, J. (2019). Does your mother know? Digital versus material spaces of queer encounter in Singapore. In C. Nash \& A. Gorman-Murray (Eds.), The geographies of digital sexuality (pp. 225-246). Singapore: Palgrave Macmillan.
Massey, D. (1994). Space, place and gender. Oxford: Blackwell Publishers.

Miles, S. (2017). Sex in the digital city: Location-based dating apps and queer urban life. Gender, Place and Culture, 24(11), 1595-1610.

Miles, S. (2018). Still getting it on online: Thirty years of queer male spaces brokered through digital technologies. Geography Compass, 12, 1-13.

Ministry of Commerce of the People's Republic of China. (2020, June 3). Hefei, foshan jinsheng xin yixian chengshi! 2020 zuixin 1-5 xian chengshi paiming fabu [Hefei and Foshan are promoted to new first tier city status! The latest 2020 1-5 tier city rankings are released]. Ministry of Commerce of the People's Republic of China. Retrieved from http://coi.mofcom.gov.cn/article/y/gnxw/202006/ 20200602970434.shtml

Mowlabocus, S. (2010). Gaydar culture: Gay men, technology and embodiment in the digital age. London: Routledge.

Nash, C. (2012). The age of the "post-mo"? Toronto's gay village and a new generation. Geoforum, 49, 243-252.

Nash, C., \& Gorman-Murray, A. (2016). Digital sexualities: Section introduction. In G. Brown \& K. Browne (Eds.), The Routledge research companion to geographies of sex and sexualities (pp. 353-357). Oxon: Routledge.

Nash, C., \& Gorman-Murray, A. (2019). Queer mobilities and new spatial media. In C. Nash \& A. GormanMurray (Eds.), The geographies of digital sexuality (pp. 29-48). Singapore: Palgrave Macmillan.

National Bureau of Statistics of China. (2017). China statistical yearbook 2017. Beijing: China Statisitcal Press.

Pullen, C., \& Cooper, M. (2010). LGBT identity and online new media. Oxon: Routledge.

Rabari, C., \& Storper, M. (2015). The digital skin of cities: Urban theory and research in the age of the sensored and metered city, ubiquitous computing and big data. Cambridge Journal of Regions, Economy and Society, 8(1), 27-42.

Roth, Y. (2014). "Locating the scruff guy": Theorizing body and space in gay geosocial media. International Journal of Communication, 8, 2113-2133.

Statistical Bureau of Hainan Province. (2017). Hainan statisitcal yearbook 2017. Beijing: China Statisitcal Press.

Stempfhuber, M., \& Liegl, M. (2016). Intimacy mobilized: Hook-up practices in the location-based social network Grindr. Österreichische Zeitschrift für Soziologie, $41,51-70$.

Stone, A. (2018). The geography of research on LGBTQ life: Why sociologists should study the south, rural queers, and ordinary cities. Sociology Compass, 12, $1-15$.

Szulc, L. (2014). The geography of LGBTQ Internet studies. International Journal of Communication, 8, 2927-2931. 
van Doorn, N. (2011). Digital spaces, material traces: How matter comes to matter in online performances of gender, sexuality and embodiment. Media, Culture \& Society, 33(4), 531-547.

Wajcman, J. (2010). Feminist theories of technology. Cambridge Journal of Economics, 34(1), 143-152.

Wang, S. (2018). Calculating dating goals: Data gaming and algorithmic sociality on Blued, a Chinese gay dating app. Information, Communication \& Society,
23(2), 181-197.

Wu, J. (2003). From "long yang" and "Du Shi" to Tongzhi: Homosexuality in China. Journal of Lesbian and Gay Psychotherapy, 7(1/2), 117-143.

Zhao, B., Sui, D., \& Li, Z. (2017). Visualizing the gay community in Beijing with location-based social media. Environment and Planning A: Economy and Space, 49(5), 977-979.

\section{About the Author}

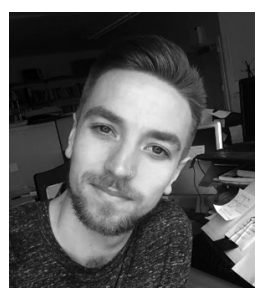

James Cummings is a Senior Research Associate at the University of East Anglia. His research explores the production of sexual identities, subjectivities, lives and spaces at the intersections of social, political and technological change in the People's Republic of China and the United Kingdom. His forthcoming monograph The Everyday Lives of Gay Men in Hainan: Community, Space and Time will be published with Palgrave Macmillan in 2021. 